\title{
EFEKTIFITAS ARANG AKTIF DARI TEMPURUNG KELAPA DALAM MENGADSORPSI LOGAM Fe PADA PELUMAS MOTOR BEKAS PAKAI
}

\author{
Rini Siskayanti' ${ }^{1)}$, Muhamad Engkos Kosim ${ }^{2)}$, Dima riawan ${ }^{3)}$. \\ ${ }^{1,2,3)}$ Jurusan Teknik Kimia, Fakultas Teknik, \\ Universitas Muhammadiyah Jakarta \\ email: rini.siskayanti@umj.ac.id
}

\begin{abstract}
Abstrak
Pelumas bekas merupakan golongan limbah B3 mengandung logam berat yang dapat menyebabkan pencemaran lingkungan. Upaya yang dapat dilakukan untuk mengurangi pencemaran ini adalah dengan cara memurnikan kembali pelumas bekas menjadi base oil-nya. Salah satunya dengan menggunakan arang aktif dari tempurung kelapa. Tujuan dari penelitian ini agar dapat mengetahui efektifitas penyerapan logam Fe oleh adsorben dengan ukuran partikel yang berbeda pada pelumas motor bekas pakai. Penelitian ini dilakukan melalui beberapa tahap yaitu tahap pembuatan arang aktif dan tahap proses adsorpsi logam oleh arang aktif. Proses adsorbsi dilakukan dengan beberapa variabel tetap yaitu dilakukan dalam temperatur ruangan $25^{\circ} \mathrm{C}$ dengan kecepatan putaran pengadukan oleh magnetic stirrer sebesar $400 \mathrm{rpm}$. Proses adsorpsi pun dilakukan dengan waktu kontak antara arang aktif dan sampel pelumas motor bekas pakai selama 60 menit dengan bobot arang aktif yang ditambahkan sebanyak $5 \mathrm{gr}$. Untuk dapat menentukan efesiensi ukuran partikel yang digunakan pada penyerapan logam Fe pelumas motor bekas pakai dibuat dengan variasi ukuran yaitu mesh 60, 80,100, 120, 140. Dari hasil penelitian diperoleh angka penyerapan logam oleh adsorben pada ukuran partikel mesh 60, 80, 100, 120, dan 140 sebesar 2,4 ppm, 8,3 ppm, 12,5 ppm, 15,4 ppm, dan 17,2 ppm dan nilai penyerapan optimal terdapat pada ukuran partikel adsorben dengan mesh 140 yaitu sebesar 17,2 ppm logam Fe dengan nilai efisiensi sebesar $8,44 \%$.
\end{abstract}

Kata Kunci: Arang aktif, logam Fe, Pelumas bekas

\section{PENDAHULUAN}

Penurunan kualitas lingkungan salah satunya diakibatkan oleh perkembangan industri yang tidak terkontrol dan limbah organik maupun anorganik yang dihasilkan dibuang tanpa atau belum sesuai dengan peraturan yang berlaku sehingga mencemari lingkungan yang meliputi udara, air, dan tanah. Salah satu aktivitas yang menghasilkan limbah dalam kehidupan sehari hari yaitu dengan membuang begitu saja pelumas mesin bekas pakai ke lingkungan tanpa adanya perlakuan atau proses khusus. Pelumas mesin bekas mengandung logam berat, diantaranya yang paling dominan adalah logam Fe yang dihasilkan dari sisa- sisa pembakaran mesin atau pun permukaan bagian dalam mesin yang terlarut dalam pelumas. Pelumas bekas merupakan golongan limbah B3 yang dapat menyebabkan tanah menjadi tandus dan kehilangan unsur haranya (Dahlan et al., 2014). Pelumas bekas pun tidak dapat larut dalam air dan juga memiliki sifat yang mudah terbakar. Oleh karena itu diperlukan upaya untuk mengurangi pencemaran lingkungan yang diakibatkan oleh pelumas bekas. Salah satu upaya yang dapat dilakukan adalah dengan cara memurnikan kembali pelumas bekas menjadi base oil-nya. Terdapat beberapa cara yang dapat dilakukan untuk memurnikan kembali pelumas bekas menjadi base oil-nya, salah satunya 
dengan menggunakan arang aktif dari tempurung kelapa. Sebelumnya telah dilakukan penelitian dengan judul "Daur ulang minyak pelumas bekas menjadi minyak pelumas dasar" dimana pada penelitian ini digunakan kombinasi antara batu bara dan karbon aktif dengan yang dapat menyerap logam $\mathrm{Pb}$ sebanyak 0,09 ppm pada kondisi perbandingan antara batu bara dan karbon aktif sebesar 500:25 gr pada temperatur $140^{\circ} \mathrm{C}$ dengan waktu kontak 100 menit. Terdapat beberapa penelitian terdahulu lainnya yang dilakukan untuk memurnikan kembali pelumas bekas di antaranya dengan menggunakan adsorben Fly Ash batu bara, Alkilbenzenesulfonat, Zeolit, Acid and Clay, dan daun nanas. Arang aktif paling mudah digunakan dalam proses adsorpsi, namun agar arang aktif dapat optimal dalam memurnikan kembali pelumas bekas, maka arang aktif perlu diaktifasi terlebih dahulu dengan menggunakan senyawa kimia. Tujuan dari penelitian ini antara lain dapat mengetahui perbedaan angka penyerapan logam oleh adsorben pada ukuran partikel yang berbeda serta dapat menentukan efesiensi ukuran partikel adsorben yang digunakan untuk penyerapan logam $\mathrm{Fe}$ pada pelumas bekas.

\section{TINJAUAN PUSTAKA}

\section{Pelumas \& Pelumasan}

Pelumas atau oli mesin merupakan campuran kompleks hidrokarbon dan senyawa-senyawa organik lain yang digunakan untuk melumasi bagian- bagian mesin mobil atau motor agar mesin bekerja secara lancar dengan cara mengurangi gaya gesek antara permukaan mesin yang saling bergesek. Pelumas dibuat dengan 70-90\% campuran minyak pelumas dasar (base oil) dan ditambah dengan bahan aditif untuk meningkatkan sifat-sifatnya. Pelumas juga berfungsi untuk membersihkan bagian-bagian mesin dari oksidasi dan mencegah terjadinya karat di dalam mesin. Fungsi lain dari pelumas adalah sebagai pelicin jalan bagi komponen-komponen tersebut, pendingin dan pembersih kotoran-kotoran yang ditinggalkan akibat terjadinya gesekan komponen tersebut. (Siskayanti \& Kosim, 2018)

Pelumasan adalah tindakan menempatkan pelumas antara permukaan yang saling bergeser untuk mengurangi keausan dan friksi. Sistem pelumasan merupakan salah satu sistem utama pada mesin. Pelumasan terhadap mesin digunakan untuk menghindari terjadinya gesekan langsung antara logam dalam mesin, sehingga tingkat keausan logam dan tingkat kerusakan mesin dapat dikurangi.dan keausan yang terjadi dapat menyebabkan temperatur disekitar mesin meningkat dan akan terus meningkat. Apabila gesekan ini tidak diatasi, akan mempengaruhi kinerja suatu mesin yang dapat menyebabkan berkurangya umur mesin dan kegagalan mesin. Hal ini membawa kerugian pada suatu industri karena berpengaruh pada produktifitasnya dan pengeluaran biaya yang besar untuk perbaikan mesin. Cara kerja pelumas adalah dengan membentuk oil film pada permukaan yang saling bergesekan. Oil film yang terbentuk sangat berpengaruh pada temperatur yang dihasilkan. Pelumas yang baik adalah pelumas yang tidak mudah mengalami perubahan viskositas jika terjadi peningkatan temperatur. Keberhasilan sistem pelumasan pada suatu mesin sangat diperlukan. Keberhasilan pelumasan ditentukan oleh tiga aspek, yaitu jenis pelumas, jumlah pelumas, dan metode pelumasan. Dengan pemilihan dan penggunaan pelumasan yang tepat diharapkan dapat mengatasi gesekan dan keausan yang berlebih sehingga dapat memperpanjang umur mesin dan pengeluaran biaya jadi berkurang. Besarnya gesekan bisa menyebabkan mesin mengalami overheat hingga macet atau menyebabkan kerusakan pada silinder, piston, klep, lahar dan lainnya, seperti ketidakberesan pompa oli, kebocoran saluran oli, dan bisa juga karena faktor salah pemakaian jenis oli itu sendiri. Proses pembakaran dapat menimbulkan oksidasi sehingga menghadirkan kerak dan korosi pada logam.

\section{Arang Aktif}

Arang aktif adalah suatu karbon yang mempunyai kemampuan daya serap yang baik terhadap anion, kation, dan molekul dalam bentuk senyawa organik dan anorganik, baik berupa larutan maupun gas. Beberapa bahan yang mengandung banyak karbon dan terutama yang memiliki pori dapat digunakan untuk membuat arang aktif. Pembuatan arang aktif dilakukan melalui proses aktivasi arang 
dengan cara fisika atau kimia di dalam retort. Perbedaan bahan baku dan cara aktivasi yang digunakan dapat menyebabkan sifat dan mutu arang aktif berbeda pula. Arang aktif digunakan antara lain dalam sektor industri (pengolahan air, makanan dan minuman, rokok, bahan kimia, sabun, lulur, sampo, cat dan perekat, masker, alat pendingin, otomotif), kesehatan (penyerap racun dalam saluran cerna dan obatobatan), lingkungan (penyerap logam dalam limbah cair, penyerap residu pestisida dalam air minum dan tanah, penyerap emisi gas beracun dalam udara, meningkatkan total organik karbon tanah, mengurangi biomassa mikroba dan agregasi tanah) dan pertanian (meningkatkan keberhasilan perbanyakan tanaman secara kultur jaringan dan kesuburan media tanaman serta mencegah pembusukan akar). Arang aktif dapat digunakan untuk mengadsorpsi partikel dari senyawa kimia tertentu tergantung besar atau volume pori-pori arang aktif dan luas permukaan partikel yang diserap. Kebutuhan arang aktif semakin meningkat seiring dengan kebutuhan industri akan bahan pembersih dan penyerap dan juga bahan pengemban katalisator. Arang aktif dapat dihasilkan dari bahan- bahan yang mengandung karbon atau dari arang yang diaktivasi untuk mendapatkan permukaan yang lebih luas (Hasyim, 2016). Arang aktif dapat dibuat dengan menggunakan arang tempurung kelapa yang diaktifasi terlebih dahulu. Aktifasi arang aktif adalah suatu perlakukan yang bertujuan untuk memperbesar pori-pori arang aktif dengan cara memecahkan ikatan hidrokarbon atau mengoksidasi molekul-molekul permukaan sehingga arang mengalami perubahan sifat, baik fisika maupun kimia, yaitu luas permukaannya bertambah besar dan berpengaruh terhadap daya adsorpsi. Proses yang melibatkan oksidasi selektif dari bahan baku dengan udara, juga digunakan baik untuk pembuatan arang aktif sebagai pemucat maupun sebagai penyerap uap. Bahan baku dikarbonisasi pada temperatur $400-500^{\circ} \mathrm{C}$ untuk mengeleminasi zat-zat yang mudah menguap. $\mathrm{HCl}$ dapat digunakan sebagai aktivator karena $\mathrm{HCl}$ dapat menghilangkan oksida- oksida logam dalam arang yang menutupi pori-pori.

Adapun pembuatan arang aktif melalui dua cara:

\section{a. Proses Kimia}

Bahan baku dicampur dengan bahan-bahan kimia tertentu. Selanjutnya campuran tersebut dibentuk menjadi batangan dan dikeringkan serta dipotong-potong. Aktifasi dilakukan pada temperature $100^{\circ} \mathrm{C}$. Arang aktif yang dihasilkan, dicuci dengan air selanjutnya dikeringkan pada temperatur $300^{\circ} \mathrm{C}$. Dengan proses kimia, bahan baku dapat dikarbonisasi terlebih dahulu, kemudian dicampur dengan bahan-bahan kimia. Pada aktifasi kimia ini arang hasil karbonisasi direndam dalam larutan aktifasi sebelum dipanaskan.

\section{b. Proses Fisika}

Bahan baku terlebih dahulu dibuat arang. Selanjutnya arang tersebut digiling, diayak untuk selanjutnya diaktifasi dengan cara pemanasan pada temperatur $1000^{\circ} \mathrm{C}$ yang disertai pengaliran uap. Pada aktifasi fisika ini yaitu proses menggunakan gas aktifasi misalnya uap air atau $\mathrm{CO} 2$ yang dialirkan pada arang hasil karbonisasi, proses ini biasanya berlangsung pada temperatur $800-1100{ }^{\circ} \mathrm{C}$.

\section{Limbah B3}

Limbah B3 (Bahan berbahaya dan beracun) adalah limbah yang dihasilkan oleh industri yang mengandung bahan berbahaya dan beracun yang apabila dibuang ke dalam media lingkungan dapat mengancam lingkungan hidup, kesehatan dan kelangsungan hidup manusia serta makhluk hidup lainnya. Logam berat tergolong limbah bahan berbahaya dan beracun (B3) yang pada kadar tertentu dapat membahayakan lingkungan sekitarnya karena bersifat toksik bagi hewan dan manusia. Logam berat dianggap ancaman serius khususnya bagi organisme air dan logam ini memiliki kemampuan menumpuk di biota dan lingkungan alam. Pembacaan kadar logam dalam sampel dapat dilakukan dengan menggunakan alat Inductively Coupled Plasma (ICP).

Pada prinsipnya pengertian ICP adalah alat untuk mengukur kandungan unsur-unsur logam dalam contoh/sampel dengan menggunakan plasma sebagai sumber energinya. (Nugroho et al., 2005). Setiap atom mempunyai beberapa kemungkinan tingkat energi. Transisi elektron dari tingkat energi lebih tinggi 
ke tingkat energi lebih rendah menghasilkan spektrum yang sesuai dengan aturan dalam mekanika kuantum. Jika sejumlah energi dikenakan pada atom, maka akan tereksitasi dan elektron dari kulit terluar akan pindah ke tingkat energi lebih tinggi dan akan kembali satu tingkat atau lebih ke tingkat energi dasar. Instrumen (alat ukur) ICP dengan komponennya antara lain sampel introduction system, nebulizer, spray chamber, torch, electric generator optical system, signal processing system, dan spectraling, dapat menganalisis rentang konsentrasi yang lebar (wide dynamic range concentration) dari ppb sampai \% (persen). Untuk mendapatkan hasil akurat maka perlu mengkalibrasi kembali setalah beberapa kali pengukuran. Inductively Coupled Plasma (ICP) dapat menganalisa percontoh terhadap mineral untuk mengetahui kadar logam sampai satuan ppb (part per billion) dan ppt (part per trilyun).

\section{Adsorpsi}

Adsorpsi secara umum adalah proses terakumulasinya zat-zat terlarut yang terdapat dalam larutan antara dua permukaan, dapat terjadi antara cairan dan gas; cairan dan zat padat; atau cairan dan cairan lain. Walaupun proses tersebut dapat terjadi pada seluruh permukaan benda, namun yang sering terjadi adalah penggunaan bahan padat yang menyerap partikel yang berada dalam air. Bahan yang akan diadsorpsi disebut sebagai adsorbat atau zat terlarut sedangkan bahan pengadsorpsi dikenal sebagai adsorben. Proses adsorpsi dibedakan atas dua bagian yaitu: adsorpsi fisika (fisisorpsi) dan adsorpsi kimia (kemisorpsi) (Erawati \& Fernando, 2018). Adsorpsi fisika atau adsorpsi Van der Waals merupakan suatu fenomena yang terjadi secara reversibel sebagai akibat dari gaya tarik menarik antar molekul padatan dengan substansi yang teradsorpsi. Ssebagai contoh, apabila gaya tarik menarik antar molekul suatu padatan dengan suatu gas lebih besar dibanding gaya tarik menarik antar molekulmolekul itu sendiri, maka gas akan terkondensasi pada permukaan padatan. Adsorpsi fisika terjadi hampir pada semua permukaan dan dipengaruhi oleh suhu dan tekanan. Adsorpsi kimia, dalam bentuk reaksi kimia membutuhkan energi aktivasi, nilai panas adsorpsi kira-kira 10 sampai $100 \mathrm{kkal}^{\mathrm{mol}}{ }^{-1}$.

\section{METODOLOGI PENELITIAN}

Penelitian dilakukan melalui beberapa tahap. Pertama tahap pembuatan arang aktif dari tempurung kelapa. Proses yang digunakan dalam pembuatan arang aktif dari tempurung kelapa adalah secara Proses Kimia. Proses ini digunakan karena bahan yang digunakan mudah didapatkan dan waktu pembuatan yang relatif cepat. Setelah arang aktif diperoleh maka tahapan selanjutnya adalah proses adsorpsi dengan melakukan variasi waktu kontak pelumas bekas dan arang aktif dalam ukuran partikel yang sama. Kemudian proses adsorpsi dilakukan kembali dengan variasi ukuran partikel arang aktif dalam waktu kontak yang sama antara pelumas bekas dan arang aktif. Metode adsorpsi memiliki kelebihan yaitu lebih sederhana, biaya yang relatif murah, ramah lingkungan, tidak adanya efek samping yang beracun.

Tabel 1. Kondisi operasi arang aktif

\begin{tabular}{|l|l|}
\hline \multicolumn{1}{|c|}{ Parameter } & \multicolumn{1}{c|}{ Kondisi Operasi } \\
\hline Ukuran partikel arang aktif & Mesh 60, 80, 100, 120,140 \\
Waktu Kontak & 60 menit \\
Bobot Arang aktif & 5 gram \\
Kecepatan pengadukan & $400 \mathrm{rpm}$ \\
Suhu & $25^{\circ} \mathrm{C}$ \\
\hline
\end{tabular}


Diagram Alir Pembuatan Arang Aktif :

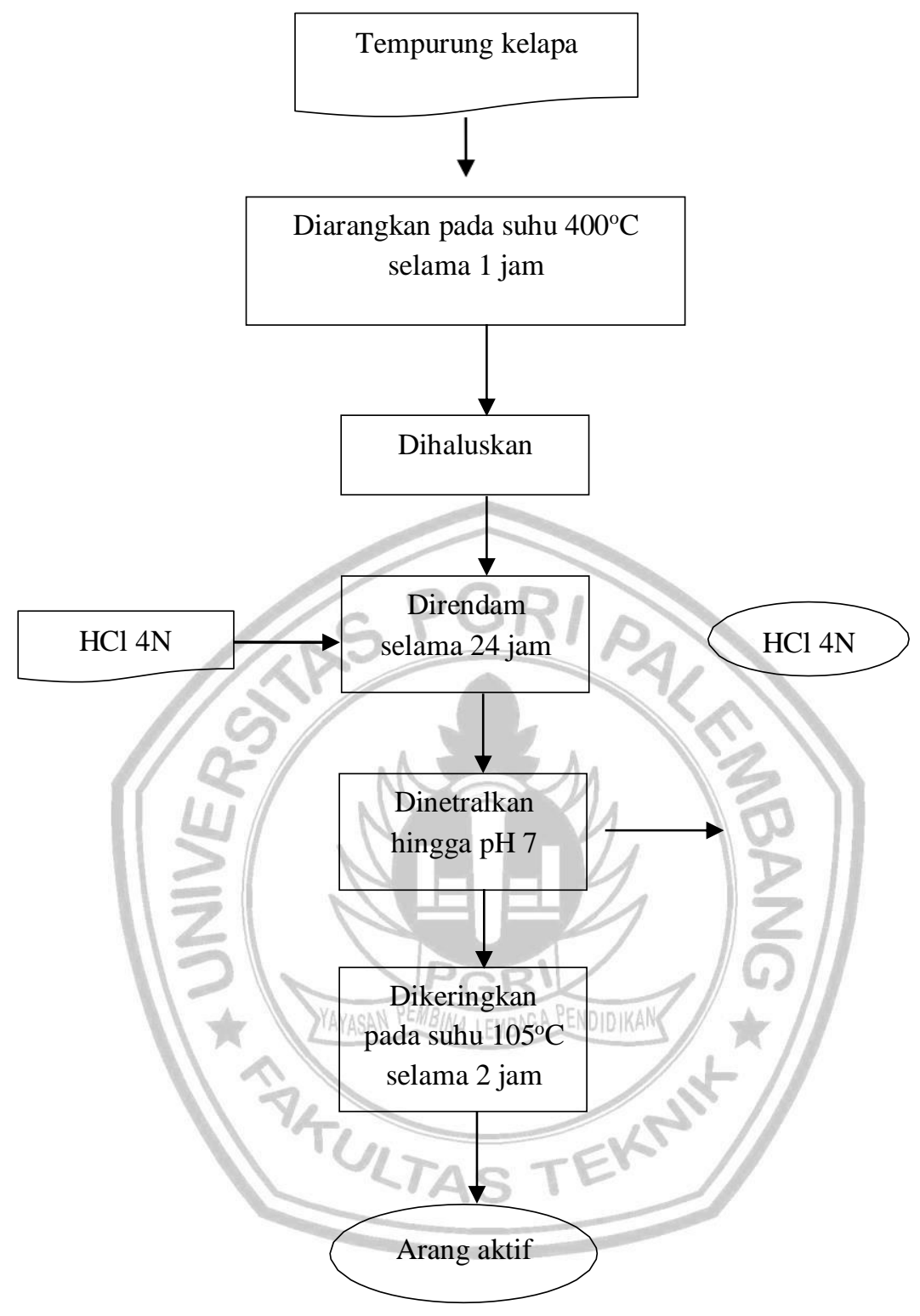

Gambar 1. Diagram alir pembuatan arang aktif 
Diagram Alir Proses Adsorpsi

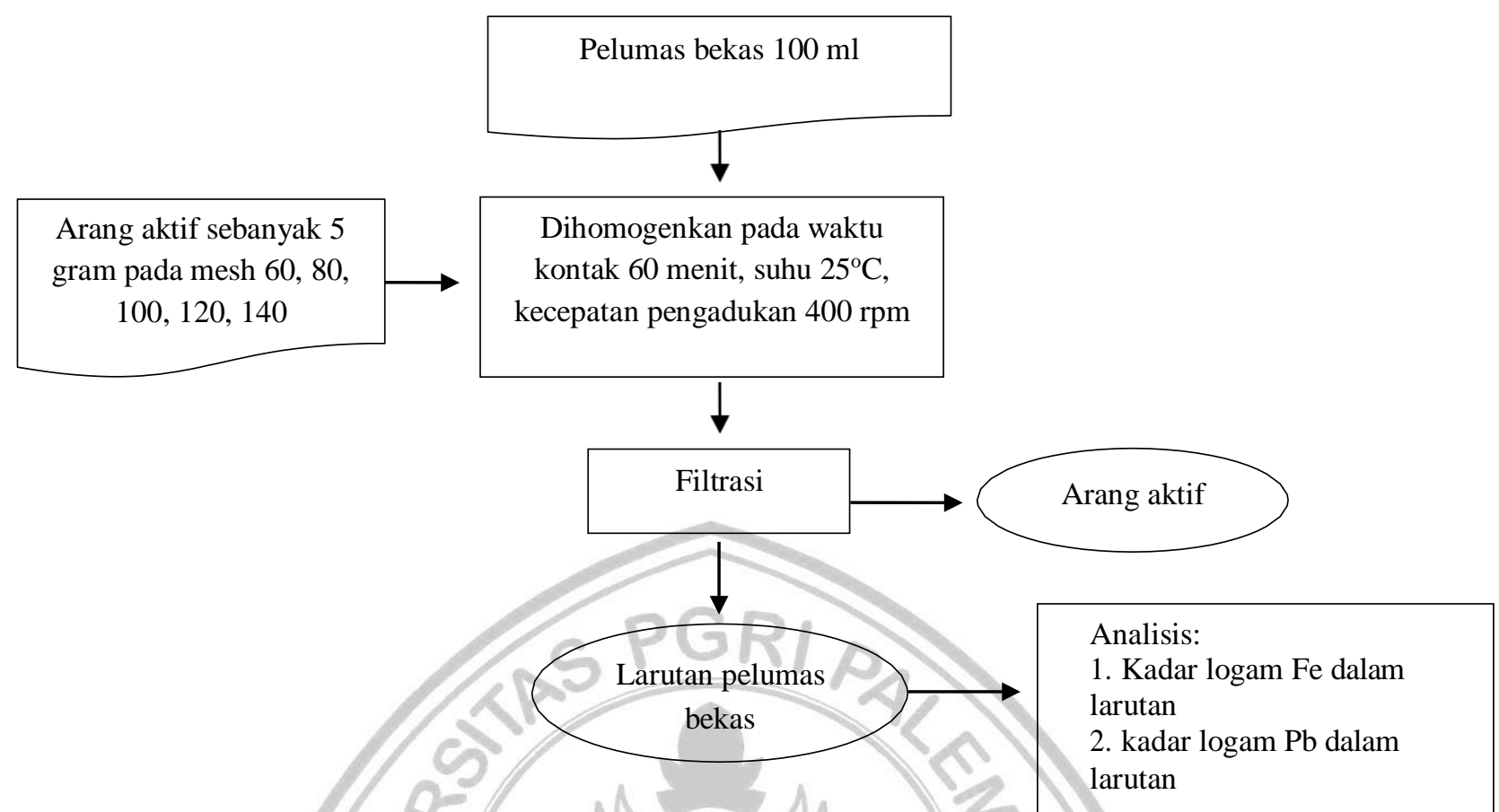

Gambar 2. Diagram alir proses adsorpsi

\section{HASIL DAN PEMBAHASAN}

Berdasarkan hasil analisa sampel pelumas yang dibaca menggunakan instrument ICP diperoleh hasil sebagai berikut:

Tabel 2. Data Hasil Analisa

\begin{tabular}{|c|c|c|c|c|}
\hline \multirow[t]{2}{*}{ No } & \multirow[t]{2}{*}{ Sampel } & $\begin{array}{c}\text { Kadar Logam } \\
(\mathrm{ppm})\end{array}$ & $\begin{array}{c}\text { Logam terserap } \\
(\mathrm{ppm})\end{array}$ & $\begin{array}{c}\text { Persen penyerapan } \\
(\%)\end{array}$ \\
\hline & & $\mathrm{Fe}$ & $\mathrm{Fe}$ & $\mathrm{Fe}$ \\
\hline 1 & Sampel Awal & 203,9 & - & - \\
\hline 2 & Mesh 60 & 201,5 & 2,4 & 1,18 \\
\hline 3 & Mesh 80 & 195,6 & 8.3 & 4,07 \\
\hline 4 & Mesh 100 & 191,4 & 12,5 & 6,13 \\
\hline 5 & Mesh 120 & 188,5 & 15,4 & 7,55 \\
\hline 6 & Mesh 140 & 186,7 & 17,2 & 8,44 \\
\hline
\end{tabular}

Penelitian ini dilakukan dengan menggunakan arang aktif sebagaiadsorben yang diharapkan dapat menyerap logam Fe pada limbah pelumas motor bekas pakai. Arang aktif yang digunakan berasal dari tempurung kelapa yang dipanaskan di dalam tanur dengan suhu $400^{\circ} \mathrm{C}$ selama $1 \mathrm{jam}$. Proses ini dinamakan proses Karbonisasi yang bertujuan untuk menghilangkan zat terbang. Pada proses ini arang hanya mempunyai kapasitas penyerapan rendah. Oleh karena itu, untuk mendapatkan arang dengan kapasitas 
ume

penyerapan yang tinggi maka dilakukan proses aktifasi arang dengan cara merendam arang di dalam larutan $\mathrm{HCl}$ selama 24 jam. Larutan $\mathrm{HCl}$ dipilih untuk mengaktifkan arang aktif karena bahannya mudah diperoleh dan harganya yang tidak terlalu mahal. Setelah perendaman menggunakan larutan $\mathrm{HCl}$, arang aktif perlu dibilas menggunakan aquadest hingga $\mathrm{pH}$ larutan mencapai angka 7 (netral). Hal ini bertujuan agar arang aktif yang akan digunakan dapat secara optimal menyerap logam yang terkandung dalam sampel.

Pada penelitian kali ini variabel bebas yang digunakan yaitu ukuran partikel dari arang aktif. Berdasarkan teori, semakin kecil ukuran pertikel maka luas permukaanya semakin besar, sehingga dengan luas permukaan yang besar maka kapasitas penyerapan oleh arang aktif juga akan semakin besar. Selain itu, semakin kecil ukuran partikel adsoben maka akan mempunyai tenaga inter molekuler yang lebih besar sehingga penyerapannya menjadi lebih baik. Mesh yang digunakan pada penelitian ini yaitu mesh 60, mesh 80, mesh 100, mesh 120, dan mesh 140. Hal ini dikarenakan keterbatasan rangkaian mesh yang terdapat di tempat dilakukannya penelitian.

Pembacaan kadar logam dalam sampel dapat dilakukan dengan menggunakan instrument Inductively Coupled Plasma (ICP). Berdasarkan hasil pembacaan terhadap sampel awal diperoleh kadar logam Fe dalam sampel sebesar 203,9 ppm.

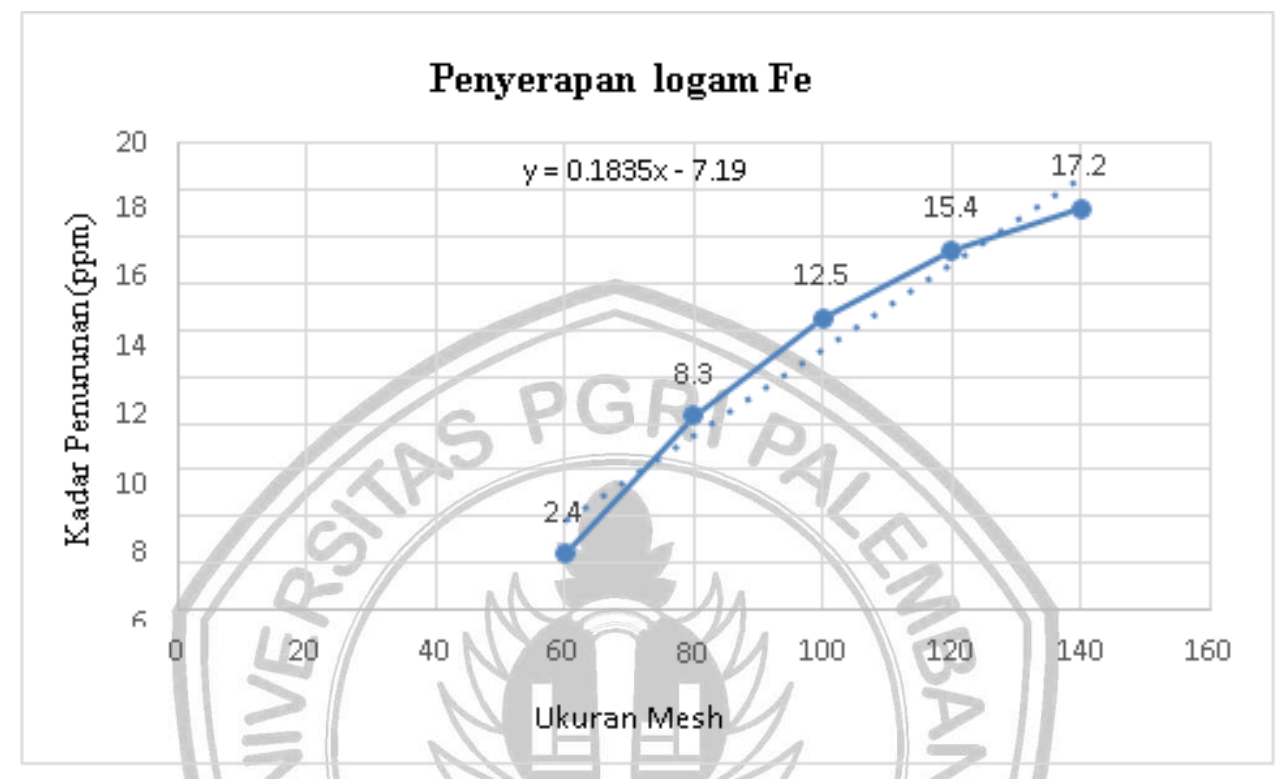

Gambar 2. Grafik Penyerapan Logam Fe

Dilihat pada gambar 2 nilai penyerapan logam $\mathrm{Fe}$ dalam sampel limbah pelumas motor bekas tertinggi terdapat pada ukuran partikel dengan mesh 140 yaitu sebesar 17,2 ppm. Sedangkan nilai penyerapan logam Fe terkecil terdapat pada ukuran partikel dengan mesh 60. Hal ini terjadi karena mesh 140 menghasilkan ukuran partikel arang aktif yang lebih kecil dibandingkan dengan mesh 60. Terjadi peningkatan jumlah logam Fe yang terserap seiring dengan bertambahnya angka mesh. Dari gambar di atas, diperoleh fungsi persamaan grafiknya yaitu $y=0.1835 x-7.19$ dan nilai regresi linear $\left(R^{2}\right)$ sebesar 0.9541 . Dari data hasil tersebut diperoleh angka efisiensi penyerapan logam Fe pada limbah pelumas motor bekas pakai pada tiap mesh nya yaitu mesh 60 sebesar 1,18\%, mesh 80 sebesar 4,07\%, mesh 100 sebesar 6,13\%, mesh 120 sebesar 7,55\%, dan mesh 140 sebesar 8,44\%. Hal ini membuktikan bahwa semakin kecil ukuran partikel arang aktif maka daya serap terhadap logam Fe pun semakin besar. 


\section{KESIMPULAN}

Berdasarkan penelitian yang telah dilakukan dapat disimpulkan bahwa:

1. Dari penelitian yang telah dilakukan diperoleh angka penyerapan logam Fe oleh adsorben dengan ukuran partikel pada mesh 60, 80, 100, 120, dan 140 berturut-turut sebesar 2,4 ppm, 8,3 ppm, 12,5 ppm, 15,4 ppm, dan 17,2 ppm.

2. Ukuran partikel arang aktif optimum untuk dapat menyerap logam Fe yaitu pada penggunaan mesh 140 yang dapat menyerap sebanyak 17,2 ppm sehingga diperoleh efisiensi peyerapan sebesar 8,44\%.

3. Semakin kecil ukuran partikel arang aktif maka daya serap terhadap logam Fe pun semakin besar.

\section{DAFTAR PUSTAKA}

Dahlan, M., Setiawan, A., \& Rosyada, A. (2014). Pemisahan Oli Bekas dengan Menggunakan Kolom Filtrasi dan Membran Keramik Berbahan Baku Zeolit dan Lempung. Jurnal Teknik Kimia Universitas Sriwijaya, 20(1), 38-45.

Erawati, E., \& Fernando, A. (2018). Pengaruh Jenis Aktivator Dan Ukuran Karbon Aktif Terhadap Pembuatan Adsorbent Dari Serbik Gergaji Kayu Sengon (Paraserianthes Falcataria). Jurnal Integrasi Proses, 7(2), 58. https://doi.org/10.36055/jip.v7i2.3808

Hasyim, U. H. (2016). Review: Kajian Adsorbsi Logam Dalam Pelumas Bekas Dan Prospek Pemanfaatannya Sebagai Bahan Bakar. Jurnal Konversi, 5(1), 11. https://doi.org/10.24853/konversi.5.1.11-16

Nugroho, A., Wahyono, H., Fatimah, S., Unsur, P., Dan, A., \& Pengembangan, S. (2005). Pengembangan metode analisis mengggunakan alat ICP AES 40 untuk penentuan unsur As dan Sb. 201-207.

Siskayanti, R., \& Kosim, M. E. (2018). Analisis Pengaruh Bahan Dasar Terhadap Indeks Viskositas Pelumas Berbagai Kekentalan. Jurnal Rekayasa Proses. https://doi.org/10.22146/jrekpros.31147 